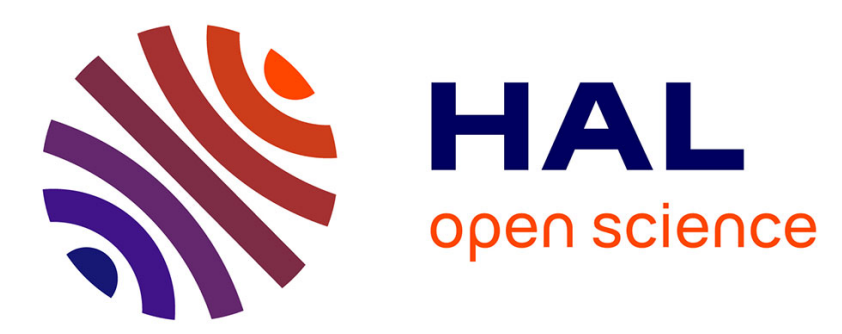

\title{
Hysteresis of the self-potential response associated with harmonic pumping tests
}

\author{
A. Revil, C. Gevaudan, N. Lu, A. Maineult
}

\section{To cite this version:}

A. Revil, C. Gevaudan, N. Lu, A. Maineult. Hysteresis of the self-potential response associated with harmonic pumping tests. Geophysical Research Letters, 2008, 35 (16), pp.L16402. 10.1029/2008GL035025 . insu-00372083

\section{HAL Id: insu-00372083 \\ https://hal-insu.archives-ouvertes.fr/insu-00372083}

Submitted on 30 Jul 2020

HAL is a multi-disciplinary open access archive for the deposit and dissemination of scientific research documents, whether they are published or not. The documents may come from teaching and research institutions in France or abroad, or from public or private research centers.
L'archive ouverte pluridisciplinaire HAL, est destinée au dépôt et à la diffusion de documents scientifiques de niveau recherche, publiés ou non, émanant des établissements d'enseignement et de recherche français ou étrangers, des laboratoires publics ou privés. 


\title{
Hysteresis of the self-potential response associated with harmonic pumping tests
}

\author{
A. Revil, ${ }^{1,2}$ C. Gevaudan, ${ }^{1}$ N. Lu, ${ }^{3}$ and A. Maineult ${ }^{4}$ \\ Received 18 June 2008; revised 12 July 2008; accepted 18 July 2008; published 22 August 2008.
}

[1] Harmonic pumping tests performed in an unconfined aquifer are responsible for a non-linear and phase shifted behavior of the self-potential response recorded at the ground surface with respect to the change in the pressure heads of the aquifer. The observed non-linearity of the transfer function can be reproduced with a petrophysical model in which the permeability, the capillary pressure curve, and the streaming potential coupling coefficient are modelled inside a unified framework approach based on the van Genuchten parametrization including a hysteretic behaviour with the water saturation. The field equations for the hydraulic heads and the self-potential signals are solved with a finite-element code, which is used to compute the time variation of the self-potential variations over time for two numerical experiments accounting or not for hysteresis. Only the model with hysteresis can reproduce the field observations. Citation: Revil, A., C. Gevaudan, N. Lu, and A. Maineult (2008), Hysteresis of the self-potential response associated with harmonic pumping tests, Geophys. Res. Lett., 35, L16402, doi:10.1029/2008GL035025.

\section{Introduction}

[2] The self-potential method is a passive method consisting in measuring the electrical potential response, at the ground surface of the Earth or in boreholes, associated with natural polarization mechanisms occurring into the ground. Two major contributions are redox phenomena [Naudet et al., 2004; Maineult et al., 2006] and streaming potential associated with ground water flow [Crespy et al., 2008]. Recent works [Rizzo et al., 2004; Straface et al., 2007] have demonstrated the usefulness of the self-potential method to monitor pumping and recovery tests. These works have presented a comprehensive formulation of the streaming potential response associated with ground water flow. In addition, Naudet et al. [2004] and Rizzo et al. [2004] showed how separate the redox and streaming contributions to analyze them separately. These works were however restricted to water-saturated rocks. Recently, the streaming potential theory has been extended as a function of the saturation of the water phase including hysteresis and

\footnotetext{
${ }^{1}$ Department of Geophysics, Colorado School of Mines, Golden, Colorado, USA.

${ }^{2}$ Equipe Volcan, LGIT, UMR5559, Université de Savoie, CNRS, Le Bourget-du-Lac, France.

${ }^{3}$ Department of Engineering, Colorado School of Mines, Golden, Colorado, USA.

${ }^{4}$ UMR7154, Institut de Physique du Globe de Paris, Université ParisDiderot, CNRS, Paris, France.
}

Copyright 2008 by the American Geophysical Union. 0094-8276/08/2008GL035025 the non-linearity of the relationship between the streaming potential and the pressure of the water phase [Linde et al., 2007; Revil et al., 2007].

[3] Maineult et al. [2008] performed harmonic pumping tests during which the self-potential response was measured at the ground surface and in boreholes with non-polarizing electrodes. They observed a non-linear self-potential response at the ground surface that was phase shifted with respect to the harmonic variations of the hydraulic heads. At the opposite, the self-potential variations with time recorded below the water table were harmonic. If this behavior can be related to the properties of the capillary fringe, these observations could be the basis of a novel, non-intrusive method to evaluate the capillary pressure curve and relative permeability [Maineult et al., 2008]. Measurements of the self-potential response made during pumping tests made and in a low-frequency band could allow characterizing non-intrusively the dynamic capillary pressure curve and the dynamic relative permeability function at different velocities of the water front.

[4] In the present letter, we use, for the first time, the theory developed by Revil et al. [2007] and Linde et al. [2007] to explain the field observations made by Maineult et al. [2008]. We are especially interested to connect the parameters controlling the capillary pressure curve and relative permeability to the non-linearity of the self-potential response associated with harmonic fluctuations of the hydraulic head near the well.

\section{Background Theory}

[5] The flow of water through the porous media in unsaturated conditions is given by the Richards equation [Richards, 1931]:

$$
\phi \frac{\partial S_{w}}{\partial t}+\nabla\left[\frac{K\left(S_{w}\right)}{\rho_{w} g} \nabla\left(P_{c}\left(S_{w}\right)\right)-K\left(S_{w}\right) \hat{z}\right]=Q_{w},
$$

where $\phi$ is the porosity, $S_{w}$ is the water saturation $\left(S_{w}=1\right.$ corresponds to full saturation), $t$ is the time (s), $K$ is the hydraulic conductivity $\left(\mathrm{m} \mathrm{s}^{-1}\right), \rho_{w}$ is the mass density of the pore water $\left(\mathrm{kg} \mathrm{m}^{-3}\right), g$ is the acceleration of the gravity $\left(\mathrm{m} \mathrm{s}^{-2}\right), P_{c}$ is the capillary pressure $(\mathrm{Pa}), \hat{z}$ is a vertical oriented unit vector, and $Q_{w}$ is a hydraulic source or sink term $\left(\mathrm{kg} \mathrm{s}^{-1}\right)$.

[6] The hydraulic conductivity $K$ is related to the permeability at saturation $k$ by: $\left(S_{w}\right)=k k_{r}\left(S_{w}\right) \rho_{w} g / \eta_{w}$, where $k_{r}$ (dimensionless) is the relative permeability of the porous material and $\eta_{w}$ is the dynamic viscosity of the pore water (in $\mathrm{Pa} \mathrm{s}$ ). In order to solve the Richards equation, both the capillary pressure curves $P_{\mathrm{c}}\left(S_{w}\right)$ and the relative 


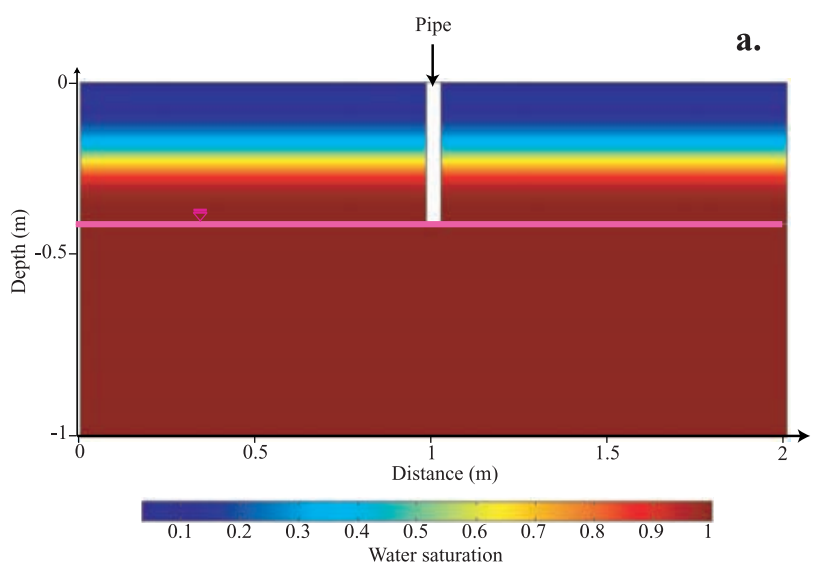

.

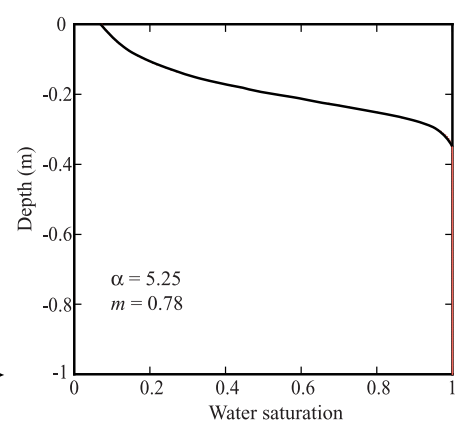

Figure 1. Sketch of the sandbox used for the numerical simulations. (a) Geometry of the system with the position of the sandbox at the reference (initial) time of the numerical experiment. (b) Saturation versus depth in the sandbox.

permeability curves $k_{r}\left(S_{w}\right)$ are required. We use the van Genuchten model [van Genuchten, 1980]:

$$
\begin{gathered}
P_{c}=\frac{1}{\alpha}\left(S_{e}^{-1 / m}-1\right)^{1-m}, \\
k_{r}=\sqrt{S_{e}}\left[1-\left(1-S_{e}^{1 / m}\right)^{m}\right]^{2},
\end{gathered}
$$

where $S_{e}=\left(S_{w}-S_{w r}\right) /\left(1-S_{w r}\right)$ and $S_{w r}$ are the effective and residual water saturation, respectively, and $\alpha\left(\mathrm{Pa}^{-1}\right), m$ (dimensionless), and $n$ (dimensionless) are the van Genuchten parameters. Other parametrizations of the capillary pressure and relative permeability curves are possible and can be related to the pore size distribution of the porous material. However, we point out that all the conclusions obtained below are strictly independent of the choice of the capillary pressure or relative permeability parametrizations used for the calculations.

[7] The flow of the pore water drags also the excess of electrical charge contained in the diffuse part of the electrical double layer. This creates the source current density $\mathbf{j}_{S}$ (in $\mathrm{A} \mathrm{m}^{-2}$ ). The total electrical current density is given by $\mathbf{j}=-\sigma \nabla \varphi+\mathbf{j}_{S}$, where $\sigma$ is the electrical conductivity of the material $\left(\mathrm{S} \mathrm{m}^{-1}\right)$ and $\varphi$ is the electrical (self-) potential (in $\mathrm{V}$ ). In unsaturated conditions, $\mathbf{j}_{S}$ can be expressed as a function of the saturation by $\mathbf{j}_{S}\left(S_{w}\right)=\bar{Q}_{V} \mathbf{u} / S_{w}$ [Revil et al., 2007; Linde et al., 2007], where $\bar{Q}_{V}$ is the excess charge density of the pore water at saturation. Jardani et al. [2007] showed that the charge density $\bar{Q}_{V}$ can be determined from the intrinsic permeability of the material at saturation according to $\log _{10} \bar{Q}_{V}=-9.2-0.82 \log _{10} k\left(\bar{Q}_{V}\right.$ is expressed in $\mathrm{C} \mathrm{m}^{-3}$ and $k$ in $\mathrm{m}^{2}$ ).

[8] If surface conductivity of the grain can be neglected, the electrical conductivity of the partially saturated porous material is given by the second Archie law: $\sigma\left(S_{w}\right)=\sigma_{s a t} S_{w}^{n}$ [e.g., Revil, 1999], $\sigma_{\text {sat }}$ is the electrical conductivity of the saturated porous material and $n$ is called the second Archie exponent. The continuity equation is $\nabla \cdot \mathbf{j}=0$. Using these equations, the electrical potential is obtained by solving a
Poisson equation with a source term determined from the solution of the Richards equation [see Bolève et al., 2007].

\section{Forward Modeling}

[9] The equations described in section 2 are solved with Comsol Multiphysics 3.3. We consider a fictitious sandbox with a rectangular shape, a height and width of $1 \mathrm{~m}$ and a length of $2 \mathrm{~m}$. We simulate numerically a harmonic pumping test and we compute the self-potential response by solving the partial differential equations described in Section 2. The harmonic pumping test is made from a vertical insulating pipe with a diameter of $4 \mathrm{~cm}$. This pipe is located at the middle of the sandbox and reaches a depth of $40 \mathrm{~cm}$. The simulated sandbox is assumed to be filled with the same sand than used by Linde et al. [2007] for their drainage experiment. At the beginning of the simulation, the water table is located at a depth of $40 \mathrm{~cm}$, therefore at the same level than the outlet of the pipe (Figure 1). We use the following parameters: $\phi=0.34, k=7.9 \times 10^{-12} \mathrm{~m}^{2}$, $\sigma_{\text {sat }}=0.012 \mathrm{~S} \mathrm{~m}^{-1}, \bar{Q}_{V}=0.48 \mathrm{C} \mathrm{m}^{-3}, n=1.6\left(\rho_{w}=1000 \mathrm{~kg}\right.$ $\mathrm{m}^{-3}$ and $\left.\eta_{w}=1.14 \times 10^{-3} \mathrm{~Pa} \mathrm{~s}\right)$. The side and bottom boundaries of the tank are impervious. We consider a free water table. We impose an harmonic variation of the pressure head at the bottom of the pipe. Consequently, the head pressure is successively positive and negative simulating water injection and pumping phases. The pressure head varies between the 0.5 and $-0.5 \mathrm{~m}$, between time 0 and $(12 \pi)$ minutes. Inside the sandbox, the piezometric level varies freely. In the initial reference state, there is no flow, so the total current density is zero. The side boundaries and top and bottom boundaries are insulating.

[10] We make two simulations. In Experiment 1, the values of $\alpha$ and $m$ are kept as constants with independent of the saturation (no hysteresis). We use $\alpha=5.25 \mathrm{~Pa}^{-1}$ and $m=0.78$. In Experiment 2, we consider that $\alpha$ and $m$ follow a sinusoidal temporal variation in phase with the pressure head variation. Thus, the value of $\alpha$ and $n$ varies respectively between a maximum of $7 \mathrm{~Pa}^{-1}$ for $\alpha$ and 0.83 for $m$ during injection phases and a minimum of $3.5 \mathrm{~Pa}^{-1}$ for $\alpha$ and 0.67 for $m$ during pumping phases. The resulting shape of the relative permeability curve versus saturation is shown 


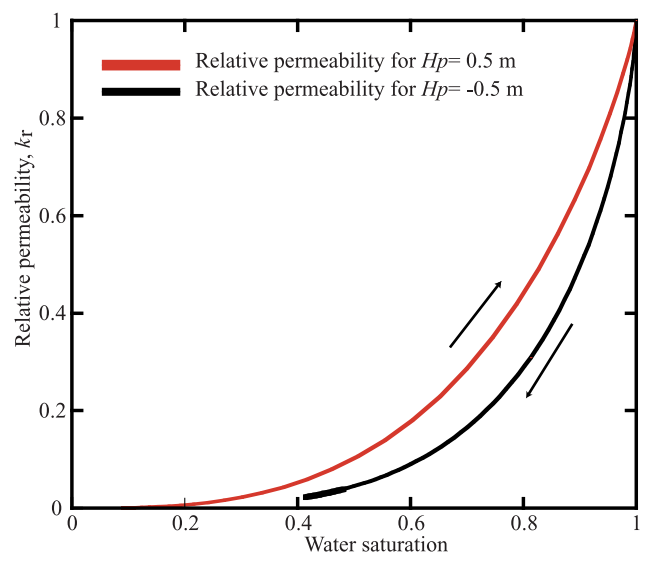

Figure 2. Variation of the relative permeability for the Experiment 2.

in Figure 2. This arbitrary parametrization is made to simulate the hysteresis occurring during the saturation/ desaturation processes.

[11] A snapshot of the water saturation during injection and pumping is shown in Figure 3. The efficiency of injecting water is higher than the efficiency in removing water from the tank. Therefore, the water level in the tank increases over time. It reaches a steady-state value after $\sim 20$ cycles). A snapshot of the resulting self-potential response is shown in Figure 4. Two self-potential stations are followed over time: Point 1 (located at the top surface of the tank) and Point 2 (located below the outlet of the capillary). The selfpotential responses recorded at Points 1 and 2 are shown in Figure 5 for Experiments 1 and 2, respectively. The trend in the self-potential response at the top of the tank is due to the evolution with time of the saturation in the vadose zone. At the opposite, there is no trend below the water table. Once this trend is removed, the self-potential response is harmonic everywhere in the tank in Experiment 1. However, the selfpotential response exhibits a phase-shifted non-linear behavior at the top surface of the tank in Experiment 2 that is consistent with the field observations of Maineult et al. [2008].

[12] Another observation resulting from the numerical experiment that is also consistent with the field data of Maineult et al. [2008] is the observed phase shift between the self-potential signals measured at the ground surface and the variations of the pressure heads of the aquifer. At the opposite, the self-potential signals measured below the water table are always in phase with the variations of the heads (the reversal of the polarity is due to the fact that the streaming potential coupling coefficient is negative). Therefore, all the field observations made by Maineult et al. [2008] can be reproduced by the numerical model.

\section{Inverse Modeling}

[13] The inverse modelling is performed by minimizing the following data misfit function $\psi_{d}$ with the Simplex algorithm [Caceci and Cacheris, 1984]),

$$
\psi_{d}=\left\|\mathbf{W}_{d}\left(\mathbf{G}(\mathbf{m})-\varphi_{d}\right)\right\|_{2},
$$

where $\|\mathbf{v}\|_{2}=\left(\mathbf{v}^{T} \mathbf{v}\right)^{1 / 2}$ denotes the Euclidian $\left(L_{2}\right)$ norm, $\mathbf{G}$ (m) corresponds to the forward model, $\mathbf{m}$ is the vector of the van Genuchten parameters entering equations (2) and (3) (using the hysteretic behaviour discussed for Experiment 2), $\varphi_{d}$ is a vector corresponding to the self potential data at the ground surface and in boreholes, and $\mathbf{W}_{d}=\operatorname{diag}\left\{1 / \varepsilon_{1}, \ldots\right.$, $\left.1 / \varepsilon_{N}\right\}$ is a square diagonal weighting matrix (the diagonal elements are the reciprocal of the standard deviation $\sigma_{\mathrm{i}}$ squared $\varepsilon_{\mathrm{i}}=\sigma_{\mathrm{i}}^{2}$ while the other components are set to zero if the noise on the data is uncorrelated). In the present case, we apply this strategy to our synthetic data of Experiments 1 and 2 (using $\varepsilon_{\mathrm{i}}=1$ ). The a prior values of the parameters (and $m$ and the functional used to mimic hysteresis) are chosen randomly inside the range $\alpha_{\mathrm{a}}$ prior $\in[1-10] \mathrm{Pa}^{-1}$ and $m_{\text {a prior }} \in[0.10-0.90]$. For Experiment 1 , the result of the inversion yields $\alpha=5 \pm 1 \mathrm{~Pa}^{-1}$ and $m=0.85 \pm 0.05$. For Experiment 2, the inverted results allow to compute the capillary pressure and relative permeability curves. The $R^{2}$ for the correlation between these curves and the curves used for the model is 0.95 . Therefore, we are able to recover successfully the values of the van Genuchten parameters.

\section{Concluding Statements}

[14] The self-potential method can be used to probe nonintrusively, and possibly in real time, the parameters char-

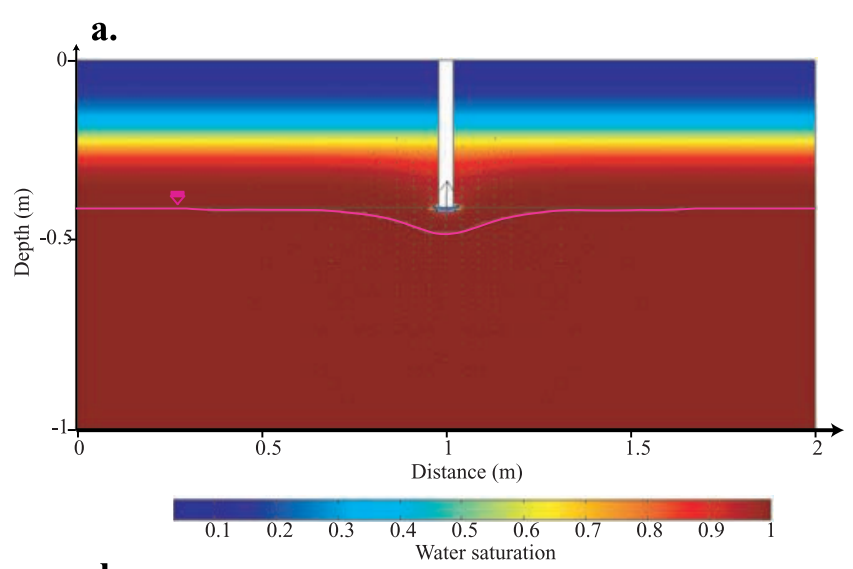

b.

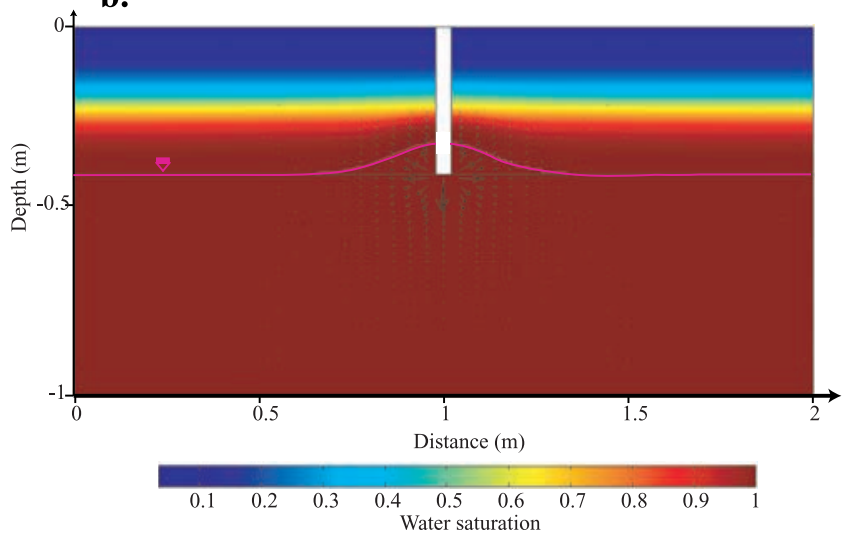

Figure 3. Simulation of the saturation in the sandbox at two different times (Experiment 1). (a) At the time where the water table reaches its lowest position. (b) At the time where the water table reaches its highest position. The position of the water table is shown by the plain line. The arrows represent the direction and strength of the Darcy velocity. 

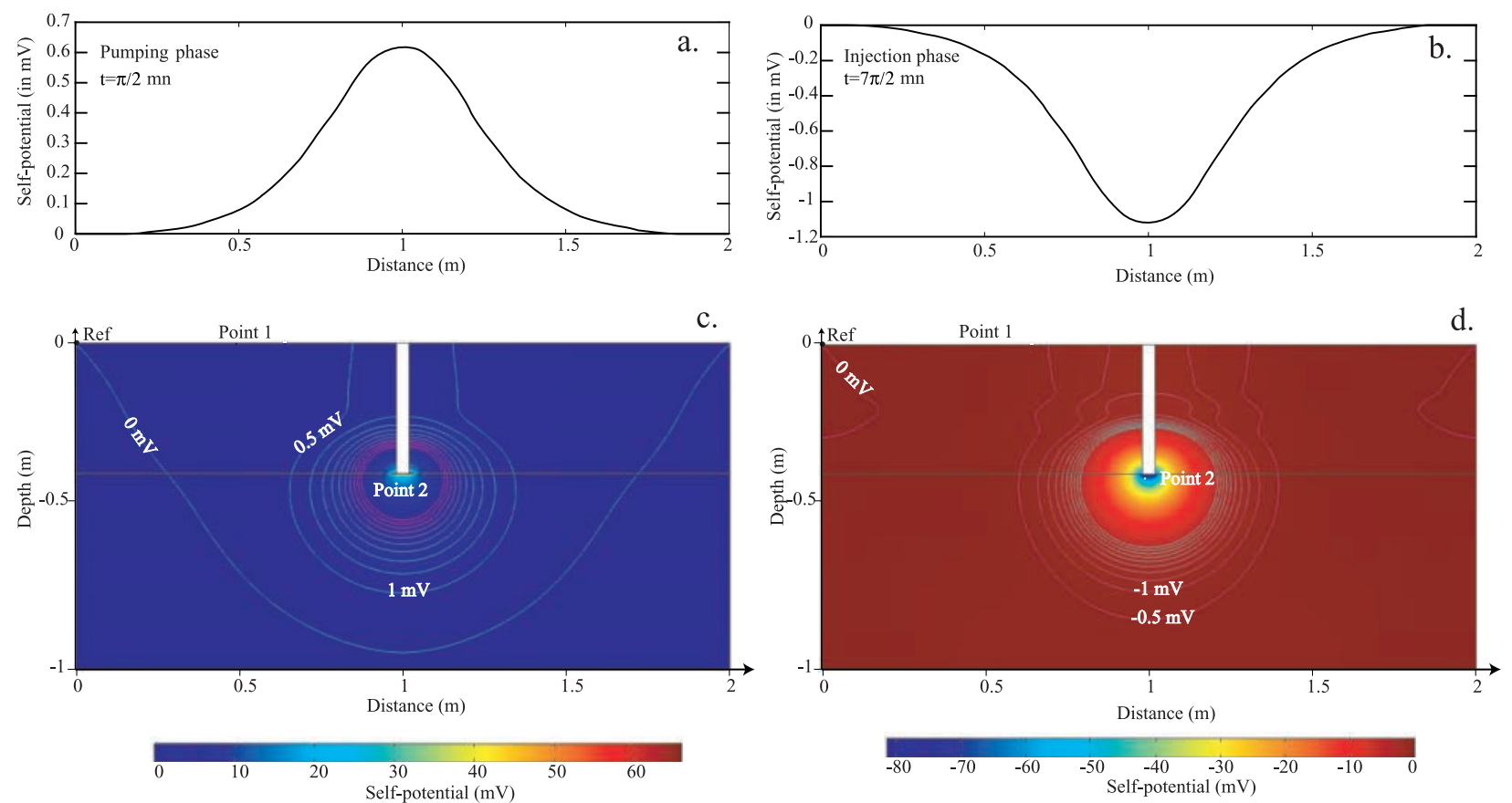

Figure 4. Numerical simulation of the self-potential response (Experiment 1). (a and c) At $t=\pi / 2$ minutes. (b and d) At $t=$ $7 \pi / 2$ minutes. The position of the reference electrode is shown on the left-hand side of the tank. Note the position of Points 1 and 2 in the tank.
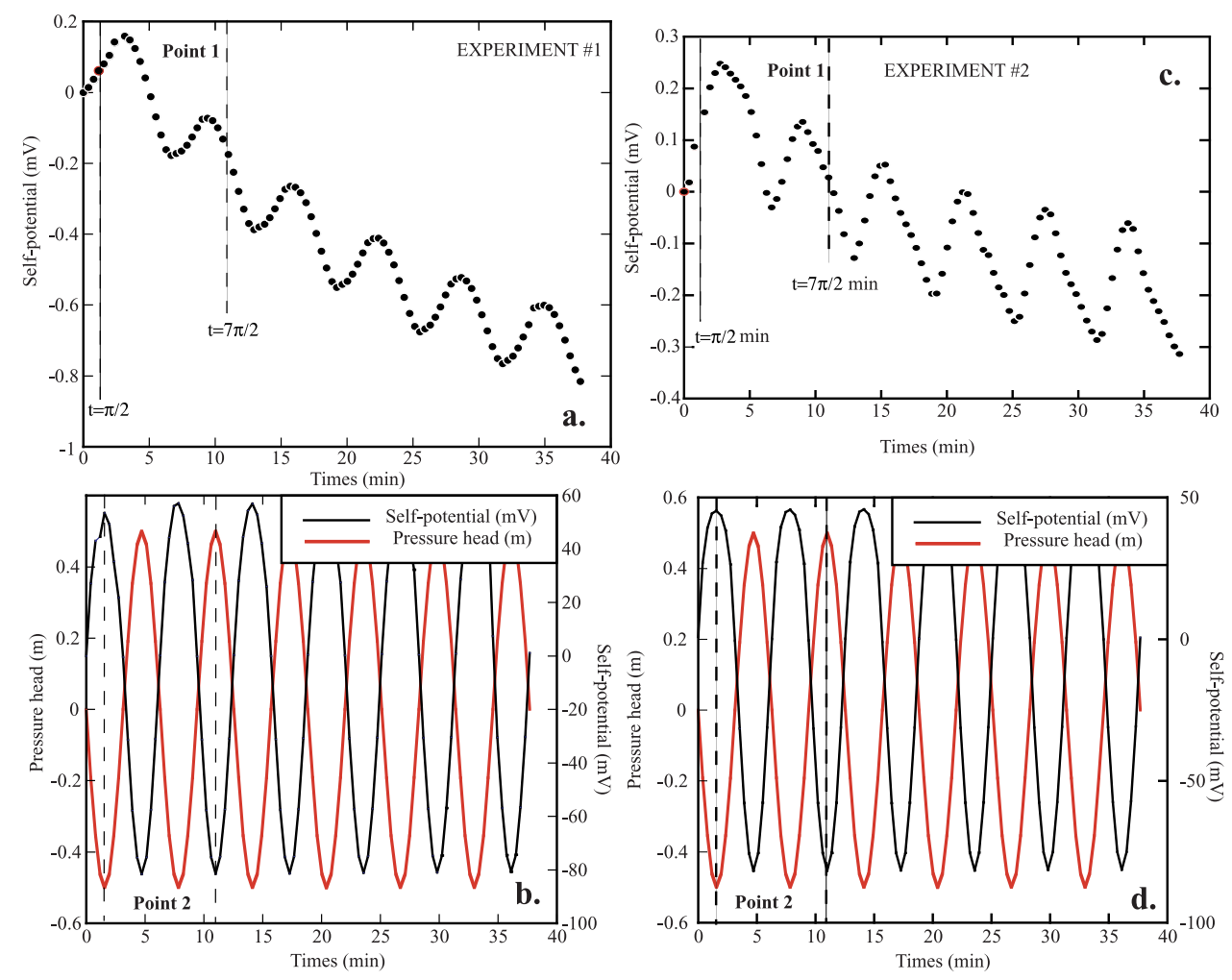

Figure 5. (a) Time variation of the self-potential response for Experiment 1 (hysteresis not accounted for) at Point 1 located at the top surface of the tank. (b) At Point 2 (located at the outlet of the pipe), we observe that the time variation of both the hydraulic head and the self-potential are harmonic. Once corrected for the trend, the self-potential response recorded by Point 1 is also harmonic (not shown here). (c) Time variation of the self-potential response of Experiment 2 at Point 1. (d) At Point 2, we observe that the time variation of both the hydraulic head and the self-potential are still harmonic. However, the self-potential response of Point 1 exhibits a non-linear, phase-shifted, behavior. 
acterizing the capillary pressure and relative permeability curves for an unconfined aquifer. Because the frequency of the harmonic pumping tests can be changed, it is also possible to analyze non-intrusively the influence of the velocity of the water front upon the capillary pressure and relative permeability curves. An extension of the present model to oil and gas reservoirs is also possible. The selfpotential approach offers therefore a non-intrusive method to access the parameters describing the capillary pressure and the relative permeability curves of the vadose zone at the level of the capillary fringe.

[15] Acknowledgments. We thank the ANR-CNRS-INSU-ECCO (project POLARIS II). This paper is IPGP contribution 2402. We thank the AE P. Kumar, K. Titov and an anonymous referee for their constructive reviews.

\section{References}

Bolève, A., A. Revil, F. Janod, J. L. Mattiuzzo, and A. Jardani (2007), Forward modeling and validation of a new formulation to compute self-potential signals associated with ground water flow, Hydrol. Earth Syst. Sci., 11(5), 1661-1671.

Caceci, M. S., and W. P. Cacheris (1984), Fitting curves to data, the Simplex algorithm is the answer, Byte, 9, 340-362.

Crespy, A., A. Revil, N. Linde, S. Byrdina, A. Jardani, A. Bolève, and P. Henry (2008), Detection and localization of hydromechanical disturbances in a sandbox using the self-potential method, J. Geophys. Res., 113, B01205, doi:10.1029/2007JB005042.

Jardani, A., A. Revil, A. Bolève, A. Crespy, J.-P. Dupont, W. Barrash, and B. Malama (2007), Tomography of the Darcy velocity from self-potential measurements, Geophys. Res. Lett., 34, L24403, doi:10.1029/ 2007GL031907.
Linde, N., D. Jougnot, A. Revil, S. K. Matthäi, T. Arora, D. Renard, and C. Doussan (2007), Streaming current generation in two-phase flow conditions, Geophys. Res. Lett., 34, L03306, doi:10.1029/2006GL028878.

Maineult, A., Y. Bernabé, and P. Ackerer (2006), Detection of advected, reacting redox fronts from self-potential measurements, J. Contam. Hydrol., 86, 32-52.

Maineult, A., E. Strobach, and J. Renner (2008), Self-potential signals induced by periodic pumping tests, J. Geophys. Res., 113, B01203, doi:10.1029/2007JB005193.

Naudet, V., A. Revil, E. Rizzo, J.-Y. Bottero, and P. Bégassat (2004), Groundwater redox conditions and conductivity in a contaminant plume from geoelectrical investigations, Hydrol. Earth Syst. Sci., 8(1), 8-22.

Revil, A. (1999), Ionic diffusivity, electrical conductivity, membrane and thermoelectric potentials in colloids and granular porous media: A unified model, J. Colloid Interface Sci., 212, 503-522.

Revil, A., N. Linde, A. Cerepi, D. Jougnot, S. Matthäi, and S. Finsterle (2007), Electrokinetic coupling in unsaturated porous media, J. Colloid Interface Sci., 313, 315-327, doi:10.1016/j.jcis.2007.03.037.

Richards, L. A. (1931), Capillary conduction of liquids through porous media, Physics, 1, 318-333.

Rizzo, E., B. Suski, A. Revil, S. Straface, and S. Troisi (2004), Selfpotential signals associated with pumping tests experiments, J. Geophys. Res., 109, B10203, doi:10.1029/2004JB003049.

Straface, S., C. Falico, S. Troisi, E. Rizzo, and A. Revil (2007), An inverse procedure to estimate transmissivities from heads and SP signals, Ground Water, 45(4), 420-428.

van Genuchten, M. T. (1980), A closed-form equation for predicting the hydraulic conductivity of unsaturated soils, Soil Sci. Soc. Am. J., 44, $892-898$.

C. Gevaudan and A. Revil, Department of Geophysics, Colorado School of Mines, 1500 Illinois St., Golden, CO 80401, USA. (arevil@mines.edu) N. Lu, Department of Engineering, Colorado School of Mines, 1500 Illinois St., Golden, CO 80401, USA.

A. Maineult, UMR7154, Institut de Physique du Globe de Paris, Université Paris-Diderot, CNRS, Tour 14, 4 Place Jussieu, F-75005 Paris CEDEX 05, France. 